\title{
Erratum to: Barriers and Facilitators to Using 9-1-1 and Emergency Medical Services in a Limited English Proficiency Chinese Community
}

\author{
Brandon N. Ong • Mei Po Yip • Sherry Feng • \\ Rebecca Calhoun · Hendrika W. Meischke • \\ Shin-Ping Tu
}

Published online: 12 June 2011

(C) Springer Science+Business Media, LLC 2011

Erratum to: J Immigrant Minority Health

DOI 10.1007/s10903-011-9449-6

Incorrect information about the funding of this research has been erroneously published in the article. The correct statement should be:

This work was supported by The Centers for Disease Control and Prevention, Grant no. 5P01TP000297. Its contents are solely the responsibility of the authors and do not necessarily represent the official views of the Centers for Disease Control and Prevention.

The online version of the original article can be found under doi:10.1007/s10903-011-9449-6.

B. N. Ong $(\bowtie) \cdot$ M. P. Yip · S. Feng · S.-P. Tu

Division of General Internal Medicine, Department of Medicine,

Harborview Medical Center, University of Washington,

325 Ninth Avenue, Box 359780, Seattle, WA 98104, USA

e-mail: bnong@u.washington.edu

R. Calhoun · H. W. Meischke

Department of Health Services, University of Washington,

Box 357660, Seattle, WA 98195, USA 